\title{
Penentuan Prioritas Dan Kelayakan Finansial Dalam Investasi Magnetic Resonance Imaging (MRI)
}

\section{Widada, Syamsudin, Soepatini, Liana Mangifera, Muzakar Isa*}

Universitas Muhammadiyah Surakarta

Jalan A. Yani, Mendungan, Pabelan, Kec. Kartasura,

Kabupaten Sukoharjo, Jawa Tengah 57162, Indonesia

*Email: muzakar.isa@ums.ac.id

\begin{tabular}{|c|c|}
\hline Artikel Info & $\mathbf{A B S}$ \\
\hline $\begin{array}{c}\text { Dikirim: } \\
6 \text { Februari } 2020 \\
\text { Revisi: } \\
17 \text { Februari } 2020 \\
\text { Diterima: } \\
\text { 30 Maret } 2020\end{array}$ & $\begin{array}{l}\text { Penelitian ini bertujuan untuk menganalisis penentuan prioritas dan kelayakan investasi MRI. } \\
\text { Penelitian ini menggunakan pendekatan mixed method, yaitu perpaduan antara pendekatan } \\
\text { kualitatif dan kuantitaif. Penelitian ini menggunakan data primer dan sekunder. Data Primer } \\
\text { yang digunakan adalah pendapat stakeholders dalam memilih kreteria dan alternatif MRI yang } \\
\text { dikumpulkan langsung dari stakeholders terpilih. Data primer diperoleh melalui Focus Group } \\
\text { Discussion (FGD) dengan sumber data para stakeholders. Data sekunder meliputi harga dan } \\
\text { spesifikasi MRI di situs e-katalog LKPP, laporan keuangan, data jumlah pemeriksaan MRI, } \\
\text { dan data diagnose pasien. Analisis data menggunakan Analitycal Hierarchy Process (AHP) dan } \\
\text { analisis kelayakan investasi. Hasil analisis AHP menjelaskan urutan prioritas kriteria MRI } \\
\text { adalah software, hardware, asesoris dan harga, sedangkan prioritas alternatif MRI adalah GE } \\
\text { 16-CHANNEL, Philips } 1.5 \mathrm{~T} \text {, Siemens } 1.5 \mathrm{~T} \text {, dan Canon 1.5T. Investasi MRI dengan merek GE } \\
\text { dinyatakan layak dilakukan dengan karena memiliki nilai IRR diatas discount factor yang } \\
\text { diterapkan }(16 \% \text { ), nilai NPV positif, Nilai Payback Period kurang dari } 6 \text { tahun, nilai Benefit of } \\
\text { Cost ratio }>1 \text {, dan nilai PV of proceeds / Net investasi di atas } 1 \text {. }\end{array}$ \\
\hline
\end{tabular}

Kata Kunci: Hospital, Feasibility Study, MRI, AHP.

\section{Determination of Priority and Financial Feasibility in Magnetic Resonance Imaging (MRI)} Investments

\begin{abstract}
The present study aimed to analyze the determination of MRI priorities and financial feasibility. This study applied a mixed method approach, which is a combination of qualitative and quantitative approaches. This studi used primary and secondary data. Primary data used are the opinions of stakeholders in selecting criteria and alternative MRI collected directly from selected stakeholders. Primary data was obtained through Focus Group Discussion (FGD) with stakeholder data sources. Secondary data includes MRI prices and specifications on the LKPP e-catalog website, financial reports, data on MRI examinations, and patient diagnostic data. Data analysis used Analytical Hierarchy Process (AHP) and investment feasibility analysis. AHP analysis results explain the priority order of MRI criteria are software, hardware, accessories and prices, while alternative MRI priorities are GE 16-CHANNEL, Philips 1.5T, Siemens 1.5T, and Canon 1.5T. MRI investments with the GE brand are declared feasible because they have an IRR value above the applied discount factor (16\%), a positive NPV value, a Payback Period value of less than 6 years, a Benefit of Cost ratio > 1, and a PV of proceeds / Net value investment above 1.
\end{abstract}

Keyword: Hospital, Feasibility Study, MRI, AHP

Cara Sitasi :

Widada., et. Al., (2020). Penentuan Prioritas Dan Kelayakan Finansial Dalam Investasi Magnetic Resonance Imaging (MRI). Jurnal Ilmiah Manajemen dan Bisnis, 21(1), 96-104. https://doi.org/10.30596/jimb.v21i1.3982. 


\section{PENDAHULUAN}

Lingkungan industri rumah sakit terus mengalami perubahan, baik dari sisi eksternal maupun internal. Dalam perkembangannya, banyak bermunculan rumah sakit negeri dan swasta sehingga industri rumah sakit menjadi semakin kompetitif. Untuk mempertahankan keberadaan dan memenangkan persaingan, setiap rumah sakit perlu membangun keunggulan daya saing sebagai penyedia jasa pelayanan kesehatan di industri rumah sakit (Handoyo, 2019). Salah satu keunggulan yang dapat dilakukan rumah sakit adalah investasi peralatan pelayanan Radiologi Magnetic Resonance Imaging atau yang dikenal dengan MRI (Notosiswoyo, M., dan Suswati, 2004).

Peraturan Menteri Kesehatan Nomor 56 Tahun 2014 tentang Klasifikasi dan Perizinan Rumah Sakit menjelaskan rumah sakit kelas A harus menyediakan pelayanan Radiologi MRI. MRI merupakan suatu alat diagnostik muthakhir untuk memeriksa dan mendeteksi tubuh dengan menggunakan medan magnet yang besar dan gelombang frekuensi radio, tanpa operasi, tanpa penggunaan sinar- $X$, ataupun bahan radioaktif, yang menghasilkan rekaman gambar potongan penampang tubuh / organ manusia dengan menggunakan medan magnet berkekuatan antara $0,064-1,5$ tesla ( 1 tesla $=1000$ Gauss) dan resonansi getaran terhadap inti atom hydrogen (Bushberg, 2013). MRI merupakan metode rutin yang dipakai dalam diagnosis medis karena hasilnya yang sangat akurat (Notosiswoyo, M., dan Suswati, 2004). Dengan beberapa faktor kelebihan yang dimilikinya, terutama kemampuannya membuat potongan koronal, sagital, aksial dan oblik tanpa banyak memanipulasi posisi tubuh pasien sehingga sangat sesuai untuk diagnostik jaringan lunak, terutama otak, sumsum tulang belakang dan susunan saraf pusat dan memberikan gambaran detail tubuh manusia dengan perbedaan yang kontras, dibandingkan dengan pemeriksaan CTScan dan X-Ray lainnya sehingga anatomi dan patologi jaringan tubuh dapat dievaluasi secara detail (Judith, 2018).

Saat ini di rumah sakit $\mathrm{X}$ belum memiliki MRI sehingga pelayanan MRI dilakukan dengan pemeriksaan rujukan ke rumah sakit yang mempunyai fasilitas MRI dengan perjanjian kerja sama (PKS). Data permintaan pemeriksaan MRI, jumlah rujukan pemeriksaan MRI di rumah sakit pada tahun 2017 dan 2018 adalah sebagai berikut.

Tabel 1. Jumlah Rujukan Pemeriksaan MRI Tahun

\begin{tabular}{|c|c|c|c|}
\hline No & $\begin{array}{c}\text { Jenis } \\
\text { Pemeriksaan }\end{array}$ & $\begin{array}{c}\text { dan } 20 \\
\text { Tahun } \\
2017\end{array}$ & $\begin{array}{c}\text { Tahun } \\
2018\end{array}$ \\
\hline 1 & $\begin{array}{l}\text { Otak dan } \\
\text { BatangOtak }\end{array}$ & 3 & 12 \\
\hline 2 & $\begin{array}{l}\text { Dada dan } \\
\text { Jantung }\end{array}$ & 0 & 2 \\
\hline 3 & $\begin{array}{l}\text { Tulang } \\
\text { Belakang }\end{array}$ & 193 & 241 \\
\hline 4 & $\begin{array}{l}\text { Otot dan } \\
\text { Tulang }\end{array}$ & 53 & 148 \\
\hline 5 & $\begin{array}{l}\text { Pevis dan } \\
\text { Saluran } \\
\text { Kencing }\end{array}$ & 0 & 1 \\
\hline & Jumlah & 247 & 410 \\
\hline
\end{tabular}

Sumber: Rumah Sakit X, 2019

Pembiayaan pelayanan pemeriksaan MRI merupakan Cost yang harus dikeluarkan oleh rumah sakit perujuk mengingat semua pasien yang dilakukan pemeriksaan MRI adalah peserta Badan Penyelenggara Jaminan Sosial (BPJS). Tarif pemeriksaan MRI di rumah sakit rujukan mengacu dengan kebijakan tarif masing masing rumah sakit, sedangkan klaim dari BPJS mengacu dengan diagnosis dan tindakan pasien serta kelas rumah sakit berdasarkan Tarif INA-CBG's (Indonesian - Case Based Groups). Berdasarkan Peraturan Menteri Kesehatan Nomor 52 Tahun 2016, Tarif INA-CBG's adalah besaran pembayaran klaim oleh BPJS Kesehatan kepada fasilitas kesehatan rujukan tingkat lanjutan atas paket layanan yang didasarkan kepada pengelompokan diagnosis penyakit dan prosedur. Dari kondisi tersebut 
terdapat kesenjangan antara biaya pemeriksaan dan klaim MRI dari BPJS seperti dalam tabel di bawah ini.

Tabel 2. Biaya Rujukan Pemeriksaan MRI Tahun 2018

\begin{tabular}{|c|c|c|c|c|}
\hline \multicolumn{5}{|c|}{1 ahun 2018} \\
\hline No & Jenis Pemeriksaan & $\begin{array}{l}\text { Tarif } \\
\text { RS }\end{array}$ & Klaim BPJS & Selisih \\
\hline 1 & Otak dan Batang Otak & $29,293,729$ & $20,151,000$ & $-9,142,729$ \\
\hline 2 & Dada dan Jantung & $3,772,174$ & $3,918,300$ & 146,126 \\
\hline 3 & Tulang Belakang & $539,625,430$ & $664,435,000$ & $124,809,570$ \\
\hline 4 & Otot dan Tulang & $328,220,954$ & $165,686,000$ & \\
\hline \multirow{3}{*}{5} & & & & $162,534,954$ \\
\hline & $\begin{array}{l}\text { Pevis dan Saluran } \\
\text { Kencing }\end{array}$ & $2,862,419$ & $1,119,500$ & $-1,742,919$ \\
\hline & Jumlah & $903,774,706$ & $855,309,800$ & $-48,464,906$ \\
\hline
\end{tabular}

Sumber: Rumah Sakit X, 2019

Berdasarkan data Tabel 1 terdapat peningkatan pemeriksaan MRI sebesar 65.99\% pada tahun 2018 dibandingkan pada tahun 2017. Berdasarkan Table 2 terdapat selisih defisit sebesar Rp. 48,464,906.00 dari klaim BPJS dibanding tarif pemeriksaan MRI pada rumah sakit rujukan. Kepemilihan MRI lebih menguntungkan bagi rumah sakit daripada mengirim rujukan ke rumah sakit lain, sehingga perlu investasi MRI.

Noveranica et al. (2017) menjelaskan investasi MRI termasuk dalam jenis investasi jangka panjang karena jumlah dana yang diinvestasikan kembali dalam jangka waktu yang relatif lama, sehingga perlu dilakukan evaluasi kelayakan investasinya. Pemilihan MRI membutuhkan dana yang besar dan banyak aspek yang harus dipertimbangkan, yaitu tujuan yang berbeda dari setiap pemangku kepentingan, adanya berbagai kriteria dengan sifat yang berbeda seperti ekonomi, teknis, administrasi, epidemiologi, sosiologis, etis, efektivitas klinis, dan di bawah kondisi yang selalu berubah (Notosiswoyo dan Suswati, 2004). Ivlev et al., (2014) menjelaskan bahwa memilih MRI adalah sulit karena kepentingan pemangku kepentingan yang berbeda, dan banyak kriteria multidisiplin harus diambil secara tepat (Isa, M dan Istikomah, 2020). Teknologi medis memainkan salah satu peran paling penting dalam meningkatkan pengeluaran kesehatan dan merupakan faktor kunci yang menyebabkan meningkatnya biaya perawatan kesehatan (World Health Organization, 2011). Dengan demikian, menciptakan metode untuk memilih peralatan medis miliki menjadi prasyarat utama untuk mengurangi kerugian finansial, meningkatkan efektivitas operasi medis dan meningkatkan kualitas perawatan (Ivlev et al., 2014). Berdasarkan uraian di atas perlu dilakukan investasi MRI, sehingga perlu dilakukan analisis penentuan prioritas dan analisis kelayakan finansial dalam investasi MRI.

\section{METODE}

Penelitian ini menggunakan pendekatan mixed method, yaitu perpaduan antara pendekatan kualitatif dan kuantitatif (Creswell, 2016). Pendekatan kualitatif merupakan penelitian yang menggunakan analisis tanpa menggunakan prosedur analisis statistic atau metode kuantifikasi lainnya (Moleong, 2017). Pendekatan ini digunakan untuk memeriksa kondisi objek, dimana peneliti adalah instrument utama, dengan analisis data induktif, adapun pendekatan kuantitatif lebih menekankan pada makna dari pada generalisasi (Sugiyono, 2016).

Penelitian ini menganalisis kelayakan investasi MRI. Data yang digunakan dalam penelitian ini adalah data primer dan sekunder. Data Primer adalah data yang dikumpulkan langsung dari objek penelitian. Data primer diperoleh melalui Focus Group Discussion (FGD) dengan sumber data para stakeholders. Data sekunder penelitian ini meliputi harga dan spesifikasi MRI di situs ekatalog LKPP, laporan keuangan, data jumlah pemeriksaan MRI, dan data diagnose pasien. Analisis data menggunakan Analitycal Hierarchy Process (AHP) dan analisis kelayakan investasi.

AHP merupakan alat analisis untuk pengambilan keputusan yang dapat membantu kerangka berpikir manusia (Isa \& Mangifera, 2018). AHP membantu memecahkan persoalan yang kompleks dengan menstruktur suatu hirarki kriteria, pihak yang berkepentingan, hasil dan dengan 


\section{Jurnal Ilmiah Manajemen dan Bisnis}

menarik berbagai pertimbangan guna mengembangkan bobot atau prioritas (Utomo, S. Joko;Santoso, P.B.; Yuniarti, 2006). Analisis AHP dilakukan dengan beberapa tahapan. Pertama menyusun elemen kriteria spesifikasi MRI. Beberapa parameter yang menjadi acuan dalam pemilihan urutan prioritas MRI adalah ketersediaan dan kondisi hardware, software, asesoris dan harga. Kedua, menentukan alternatif merk MRI, yaitu MRI yang diunggah di website e katalaog LKPP. Ketiga, melakukan Focus Group Discussion (FGD). FGD dilakukan dengan menggundang peserta dari Instalasi Radiologi yang terdiri dari dokter Radiologi dan Radiografer. Kriteria dokter yang diundang adalah dokter penagung jawab Instalasi Radiologi atau dokter yang telah mendapatkan pendidikan lanjut tentang MRI. Sedangkan Radiografer yang diundang adalah radiografer penaggung jawab pelayanan, fisikawan medik dan Radiografer yang telah mengikuti pelatihan MRI atau pernah melakukan penelitian tentang MRI. Fasilitator FGD terdiri dari peneliti dan perwakilan dari manajemen rumah sakit yang berperan sebagai pengamat. Kegiatan FGD penentuan prioritas kriteria dengan menyampaikan pertanyaan kepada peserta FGD tentang pentingnya masing masing kriteria agar peserta menyampaikan pendapatnya tentang perbandingan diantara semua elemen kriteria berpasangan. Kegiatan FGD penentuan prioritas alternatif dengan menyampaikan pertanyaan kepada peserta FGD tentang perbandingan alternatif berdasarkan semua elemen kriteria yang telah disimpulkan Selanjutnya membandingkan diantara semua alternatif secara berpasangan berdasarkan semua elemen kriteria. Kelima, melakukan analisis hasil FGD. Melakukan analisishasil FGD dan keenam menyimpulkanhasil FGD.

Analisis keyalakan investasi dilakukan dengan beberapa tahapan dan pengujian, yang meliputi (1) menyusun biaya investasi MRI, (2) menyusun biaya operasional MRI, (3) menyusun pendapatan MRI, (4) menghitung arus kas, (5) melakukan analisis Internal Rate of Return (IRR), Net Present Value (NPV), Payback Period (PP), Benefit Cost Ratio, Profitability Index (PI), dan Break Even Point (BEP), dan (6) menyimpulkan kelayakan investasi (Noveranica, D., Hendrartini, Y., dan Hendra, 2017) dan (Syamsudin; Isa, M; Mangifera, L; Nurhayati, 2019).

\section{HASIL DAN PEMBAHASAN}

Magnetic Resonance Imaging (MRI) banyak digunakan di berbagai rumah sakit karena kemampuannya dalam memvisualisasikan jaringan non-invasif tanpa membuat pasien terkena radiasi (Ivlev et al., 2014). Saat ini banyak rumah sakit menggunakan beraneka macam jenis merek MRI. Mereka memilih MRI berdasarkan aspek hardware, software, asesoris dan harganya. Memilih MRI yang tepat bukanlah hal yang mudah, karena dalam pengelolaan rumah sakit banyak stakeholders yang terlibat. Setiap stakeholders memiliki kepentingan yang berbeda-beda, sehingga diperlukan metode yang tepat dalam pemilihan MRI. Penentuan jenis MRI dalam penelitian ini dilakukan melalui dua tahap, yaitu pemilihan kreteria MRI dan pemilihan alternatif MRI. Alat analisis yang digunakan dalam penentuan MRI adalah Analytic Hierarchy Process (AHP).

Penentuan kreteria MRI dilakukan melalui kajian pustaka dan FGD dengan stakeholders. Berdasarkan kajian pustaka dan FGD ditentukan 4 kriteria yang dalam pemilihan MRI, yaitu harga, hardware, software dan asesoris. Berdasarkan 4 kreteria tersebut, digunakan sebagai bahan pengambilan data melalui FGD dan hasilnya diolah menggunakan AHP. Hasil analisis kreteria MIR berdasarkan AHP adalah sebagai berikut. 


\section{Jurnal Ilmiah Manajemen dan Bisnis}

ISSN 1693-7619 (Print) I ISSN 2580-4170 (Online) | http://jurnal.umsu.ac.id/index.php/mbisnis

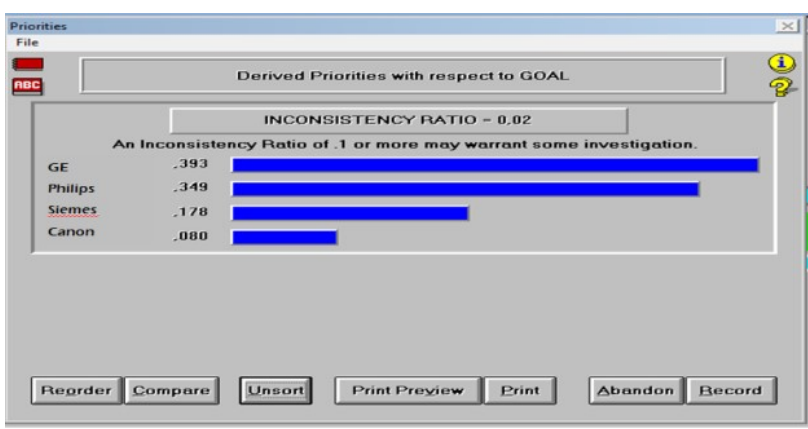

Gambar 1. Analisis Elemen Kriteria

Sumber: Hasil Analisis AHP, 2019

Hasil $A H P$ dalam penentuan prioritas kriteria MRI diperoleh nilai inconsistency ratio sebesar 0,07. Angka ini di bawah 0,1 sebagai batas maksimal nilai inconsistensi yang ditolerasi. Dengan ini, hasil penelitian dinyatakan konsisten dan hasil analisis dapat digunakan sebagai dasar penentuan kreteria pemilihan MRI.

Berdasarkan hasil AHP sebagai mana gambar 1 di atas dijelaskan bahwa software menempati kreteria prioritas pertama dalam pemilihan MRI dengnan nilai 0,54 . Artinya 54 persen stakeholder setuju dengan kreteria ini. Setelah software, stakeholder memilih hardware sebagai kreteria nomor urut 2 dengan nilai 0,27 , diikuti accesoris sebesar 0,12 dan harga sebesar 0,06 sebagai kreteria paling rendah. Dengan ini disimpulkan bahwa 4 kreteria yang diajukan semuanya disepakati, dengan urutan software, hardware, accesoris dan harga.

Tahap penentuan MRI yang kedua adalah pemilihan alternatif MRI. Penentuan alternatif MRI dilakukan melalui FGD dengan stakeholders. Berdasarkan FGD ditentukan 4 alternatif MRI, yaitu Canon Vantage Elan Vantage Elan, GE Signa Explorer, Philips Ingenia 1,5 CX, Siemes Sempra 1,5T. Berdasarkan 4 alternatif tersebut, digunakan sebagai bahan pengambilan data melalui FGD dan hasilnya diolah menggunakan AHP. Hasil analisis alternatif MRI berdasarkan AHP adalah sebagai berikut.

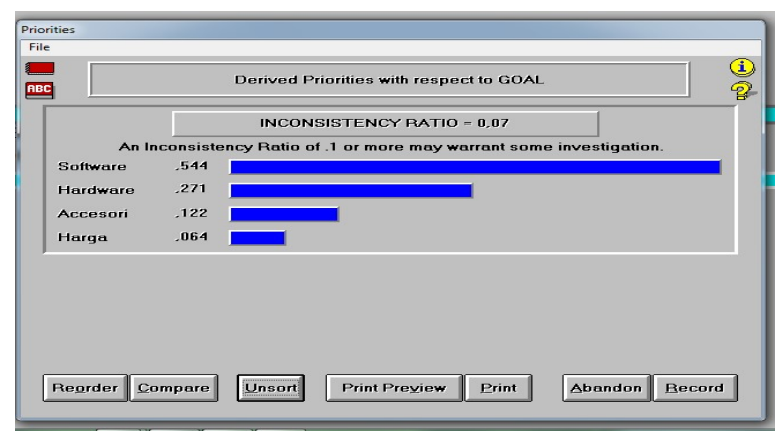

Gambar 2. Matrik Alternatif MRI

Sumber: Hasil Analisis AHP, 2019

Hasil $A H P$ dalam penentuan alternatif MRI diperoleh nilai inconsistency ratio sebesar 0,02. Angka ini jauh di bawah 0,1 dimana 0,1 merupakan batas maksimal nilai inconsistensi yang ditolerasi. Dengan ini, hasil penelitian dinyatakan konsisten dan hasil analisis dapat digunakan sebagai dasar penentuan alternatif MRI.

Berdasarkan hasil AHP sebagaimana gambar 2 di atas dijelaskan bahwa GE menempati alternatif pertama dalam pemilihan MRI dengnan nilai 0,39. Artinya 39 persen stakeholder setuju dengan alternatif ini, dan GE menjadi alternatif pertama yang dipilih. Setelah GE, stakeholder memilih Philips sebagai alternatif nomor urut 2 dengan nilai 0,34. Angka ini tidak jauh berbeda dengan nilai pemilihan alternatif GE. Alternatif yangn ketiga dan keempat adalah Siemen sebesar 0,17 dan canon sebesar 0,08. Dengan ini disimpulkan bahwa 4 alternaif yang diajukan semuanya disepakati, dengan urutan GE, Philips, Siemen dan canon.

Penentuan kretaria dan alternatif MRI bukan suatu penilaian teknis terhadap spesifikasi masing-masing MRI tetapi merupakan hasil persepsi stakeholders rumah sakit $\mathrm{X}$ terhadap spesifikasi dibandingkan dengan kebutuhan pelayanan yang diolah menggunakan AHP. Apabila stakeholders, alat analisis dan pendekatan penelitian yang digunakan berbeda ada kemungkinan hasil penelitian juga berbeda. Ivlev et al., (2014) mendukung penelitian ini dan menjelaskan MRI dengan merk Philips Ingenia 1.5T, GE 


\section{Jurnal Ilmiah Manajemen dan Bisnis}

Healthcare Discovery MR450 dan Siemens Magnetom Aera 1.5T cocok untuk rumah sakit di Republik Ceko.

Analisis Kelayakan MRI

Analisis kelayakan investasi MRI ini membahas tentang potensi pendapatan penggunaan MRI, biaya biaya yang dikeluarkan untuk pembelian MRI, biaya operasional dan perawatan, serta perhitungan kelayakan investasi (Purwana, D. dan Hidayat, 2018) dan (Noveranica, D., Hendrartini, Y., dan Hendra, 2017).

Pemasukan atas penggunaan MRI didasarkan atas jumlah pemeriksaan MRI dalam 1 tahun dikalikan besaran tarif. Jumlah pasien yang membutuhkan pemeriksaan MRI didapat dari kunjungan pasien baru dengan diagnosa sesuai dengan kriteria dari Magellan National Imaging Associates (2019), yaitu sebesar 3.000. Perkiraan pemeriksaan MRI pada tahun I seperti dalam tabel di bawah ini.

Tabel 3. Potensi Pendapatan MRI

\begin{tabular}{|c|c|c|c|c|}
\hline $\begin{array}{l}\mathrm{N} \\
\mathrm{O}\end{array}$ & Klasifikasi Tarif & Jumlah & Tarif & $\begin{array}{c}\text { Pendapatan } \\
\text { (Dalam Ribuan) }\end{array}$ \\
\hline 1 & Rawat Jalan & 1.000 & 1.317 .900 & 1.317 .900 \\
\hline 2 & $\begin{array}{l}\text { Pemeriksaan } \\
\text { khusus }\end{array}$ & 2.000 & 1.976 .900 & 3.953 .800 \\
\hline & Jumlah & & & 5.271 .700 \\
\hline
\end{tabular}

Sesuai hasil AHP di atas, dipillih GE sebagai alternatif pertama MRI. Biaya investasi MRI terdiri dari harga alat MRI, ongkos kirim dan biaya teknik. Biaya tersebut diperoleh dari katalog harga MRI.

Tabel 4. Biaya Pengadaan MRI

\begin{tabular}{llcr}
\hline No & Komp. biaya & $\begin{array}{c}\text { Harga } \\
\text { (Dalam Ribuan) }\end{array}$ & $\begin{array}{c}\text { Total Harga } \\
\text { (Dalam Ribuan) }\end{array}$ \\
\hline 1 & Alat MRI & 22.375 .000 & 22.375 .000 \\
2 & Ongkos Kirim & 223.750 & 223.750 \\
3 & Biaya Teknik & 447.500 & 447.500 \\
\hline & & & $\mathbf{2 3 . 0 4 6 . 2 5 0}$ \\
\hline
\end{tabular}

Biaya operasional MRI terdiri dari manajemen costing, perawatan dan belanja habis pakai. 1). Managemen costing terdiri dari; biaya jasa 4 dokter spesialis Radiologi, 16 Radiografer, 2 perawat dan 2 staf pelaksana pelayanan MRI. 2). Maintenance costing terdiri dari; biaya pemeliharaan MRI, listrik, air, internet dan kebersihan. 3). Belanja bahan habis pakai yang terdiri dari film dan alat tulis kantor.

Secara detail total biaya operasional pelayanan MRI rumah sakit X adalah sebagai berikut.

Tabel 5. Biaya Operasional MRI

\begin{tabular}{|c|c|c|c|c|}
\hline No & Uraian & Jumlah & Per bulan & Per tahun \\
\hline 1 & $\begin{array}{l}\text { Management } \\
\text { Costing }\end{array}$ & 1 & $87.075 .225,12$ & $1.044 .902 .701,00$ \\
\hline \multirow[t]{6}{*}{2} & $\begin{array}{l}\text { Maintenace } \\
\text { Costing }\end{array}$ & 1 & & \\
\hline & & & $73.333 .333,00$ & $879.999 .996,00$ \\
\hline & b. Listrik & 1 & $4.410 .000,00$ & $52.920 .000,00$ \\
\hline & c. Air & 1 & $380.160,00$ & $4.561 .920,00$ \\
\hline & d. Internet & 1 & $990.000,00$ & $11.880 .000,00$ \\
\hline & e. Kebersihan & 1 & $1.697 .636,36$ & $20.371 .636,32$ \\
\hline \multirow[t]{4}{*}{3} & $\begin{array}{l}\text { Bahan habis } \\
\text { pakai }\end{array}$ & & & \\
\hline & a. Fllm & 1 & $21.331 .200,00$ & $255.974 .400,00$ \\
\hline & b. ATK & 1 & $2.139 .900,00$ & $25.678 .800,00$ \\
\hline & Jumlah & & & $2.296 .289 .453,32$ \\
\hline
\end{tabular}

Sumber: Hasil Analisis (2019)

Dalam penelitian ini, peneliti mengasumsikan pertumbuhan pemeriksaan MRI adalah 1.1 pertahun sesuai dengan Peraturan Direktur Jenderal Perbendaharaan No 24 tahun 2018, yaitu pertumbuhan pemeriksaan radiologi 1.1 sehingga arus kas seperti pada tabel dibawah ini; 
Tabel 6. Arus Kas

\begin{tabular}{ccrrrr}
\hline Th & Kas Masuk & Kas Keluar & \multicolumn{1}{c}{ Kas Bersih } & \multicolumn{1}{c}{ Arus Kas } & \multicolumn{1}{c}{ Akumulasi } \\
\hline 1 & $5.271 .700 .000,00$ & $2.270 .610 .653,76$ & $3.001 .089 .346,24$ & $3.001 .089 .346,24$ & $(20.045 .160 .653,76)$ \\
2 & $5.798 .870 .000,00$ & $2.497 .671 .719,14$ & $3.301 .198 .280,86$ & $6.302 .287 .627,10$ & $(16.743 .962 .372,90)$ \\
3 & $6.378 .757 .000,00$ & $2.747 .438 .891,05$ & $3.631 .318 .108,95$ & $9.933 .605 .736,05$ & $(13.112 .644 .263,95)$ \\
4 & $7.016 .632 .700,00$ & $3.022 .182 .780,15$ & $3.994 .449 .919,85$ & $13.928 .055 .655,90$ & $(9.118 .194 .344,10)$ \\
5 & $7.718 .295 .970,00$ & $3.324 .401 .058,17$ & $4.393 .894 .911,83$ & $18.321 .950 .567,73$ & $(4.724 .299 .432,27)$ \\
6 & $8.490 .125 .567,00$ & $3.656 .841 .163,99$ & $4.833 .284 .403,01$ & $23.155 .234 .970,74$ & $108.984 .970,74$ \\
7 & $9.339 .138 .123,70$ & $4.022 .525 .280,39$ & $5.316 .612 .843,31$ & $28.471 .847 .814,05$ & $5.425 .597 .814,06$ \\
8 & $10.273 .051 .936,07$ & $4.424 .777 .808,42$ & $5.848 .274 .127,65$ & $34.320 .121 .941,70$ & $11.273 .871 .941,70$ \\
9 & $11.300 .357 .129,68$ & $4.867 .255 .589,27$ & $6.433 .101 .540,41$ & $40.753 .223 .482,11$ & $17.706 .973 .482,11$ \\
10 & $12.430 .392 .842,64$ & $5.353 .981 .148,19$ & $7.076 .411 .694,45$ & $47.829 .635 .176,56$ & $24.783 .385 .176,56$ \\
\hline \multicolumn{7}{c}{ Sumber: Hasil Analisis (2019) } & & & &
\end{tabular}

Penelitian ini menggunakan beberapa parameter kelayakan investasi (Noveranica, D., Hendrartini, Y., dan Hendra, 2017) dan (Syamsudin; Isa, M; Mangifera, L; Nurhayati, 2019). Berdasarkan daya pemasukan dan pengeluaran di atas, hasil kelayakan investasi adalah sebagai berikut (1) Nilai IRR dalam investasi MRI sebesar 17,06\%. Angka ini menunjukkan layak untuk investasi karena nilainya diatas discount factor yang diterapkan, yaitu $16 \%$. 2) Berdasarkan asumsi arus kas bersih dalam 10 tahun dinyatakan ke dalam nilai sekarang yang dikonversikan dengan tingkat suku bunga atau discount factor $16 \%$ nilainya adalah $\mathrm{Rp}$ 742.079.663,97. Hasil ini menunjukkan layak untuk investasi karena nilainya + (positif). 3 ). Perhitungan Payback Period (PP) berdasarkan asumsi arus kas selama 10 tahun adalah 5 tahun 2 bulan 19 hari. Investasi ini layak untuk dijalankan karena investasi untuk komersial rata rata 6 tahun. 4). Perhitungan aliran kas masuk dan kas keluar terdapat nilai surplus sebesar Rp 47.829.635.176,56 dan perhitungan Benefit of Cost ratio hasilnya 2,32 . Nilainya $>1$ artinya investasi layak untuk dijalankan. 5). PV of proceeds sebesar Rp.24.783.385.176,56 dan Nett Investmen sebesar Rp.20.045.160.653,76 maka $P V$ of proceeds / Net investasi adalah 1,24. Angka ini menunjukkan nvestasi bisa dijalankan karena nilainya $>$ 1. 6). Break Even Point (BEP) dihitung berdasarkan total biaya investasi Rp.20.045.160.653,76 ditambah total biaya operasional Rp.36.187.686.092,53 $=$ Rp.56.232.846.746,29 dibagi total pemasukan rerata/tahun Rp.8.401.732.126,91 $=6,69$ (6 tahun 8 bulan 8 hari). Angka ini menunjukkan investasi layak dijalankan karena BEP nya kurang dari 10 tahun.

Berdasarkan hasil analisis finansial seperti diuraikan di atas, investasi MRI ini layak dilakukan. Berbagai perhitungan analisis kelayakan finansial yang terdiri dari Internal Rate of Return (IRR), Net Present Value (NPV), Payback Period (PP), Benefit Cost Ratio, Profitability Index (PI), dan Break Even Point (BEP) menunjukkan hasil yang layak.

\section{PENUTUP}

Setiap rumah sakit harus memiliki daya saing yang kuat untuk memenangkan persaingan. Penguatan daya saing rumah sakit, dilakukan melalui optimalisasi manajemen rumah sakit, baik aspek perencanaan, pengorganisasian, pengarahan dan pengendalian. Rumah sakit harus mampu melakukan perencanaan yang baik, seperti perencanaan dalam investasi MRI. Investasi tersebut harus mempertimbangkan pendapat stakeholders dalam menentukan kreteria dan alternative MRI serta analisis kelayakan finansial. Penentuan MRI rumah sakit berdasarkan analisis $A H P$ dijelaskan bahwa kriteria MRI yang paling prioritas adalah software. Prioritas selanjutnya adalah hardware, asesoris dan terakhir harga. Hasil 
AHP juga menjelaskan bahwa prioritas alternatif MRI yang dipilih adalah GE 16-Channel, diikuti Philips 1.5T, Siemens 1.5T, dan terakhir Canon 1.5T. Investasi MRI di rumah sakit layak dilakukan dengan karena (1) nilai IRR sebesar 17,06\% dimana di atas discount factor yang diterapkan, yaitu $16 \%$. (2) nilai NPV positif, (3) Nilai Payback Period (PP) 5 tahun 2 bulan 19 hari, yaitu dibawah 6 tahun, (4) nilai Benefit of Cost ratio hasilnya 2,32, atau diatas Nilainya $>1$, (5) nilai $P V$ of proceeds / Net investasi adalah 1,24. Angka ini menunjukkan investasi bisa dijalankan karena nilainya $>1$, dan (7) BEP 6,69, yaitu kurang dari 10 tahun.

Saran yang sampaikan adalah (1) hasil penelitian bisa digunakan sebagai salah satu referensi dalam penentuan jenis dan investasi MRI. Akan tetapi masih perlu dipertimbangkan untuk melakukan diskusi dengan penyedia alat MRI untuk memperoleh penjelasan lebih detil tentang spesifikasi MRI, mengingat dengan perkembangan teknologi memungkinkan perubahan spesifikasi tiap tiap MRI, (2) penelitian selanjutnya dalam penentuan prioritas spesifikasi MRI dapat menggunakan alternative metode lainnya seperti PROMETHEE, TOPSIS, dan SAW sehingga diperoleh hasil yang lebih komprehensif, dan (3) penelitian selanjutnya untuk dalam analisis investasi supaya memasukkan aspek lain, seperti aspek pasar, SDM dan operasional teknis.

\section{REFERENSI}

Bushberg. (2013). The Essential Physics if medical Imaging. California, Third edition: Lippincott Williams \& Wilkins.

Creswell, J. W. (2016). Research Design Pendekatan Kualitatif, Kuantitatif, dan Mixed. Yogyakarta: Pustaka Pelajar.

Handoyo, D. W. I. (2019). Analisis Pengaruh Penerapan Lean Hospital Terhadap Kepuasan Konsumen Rumah Sakit PKU
Muhammadiyah Surakarta. Universitas Muhammadiyah Surakarta.

Isa, M dan Istikomah, R. (2020). Analisis Perilaku Konsumen Dalam Keputusan Pembelian Makanan Di Kota Surakart. Jurnal Manajemen Dayasaing, 21(2), 98-110.

Isa, M., \& Mangifera, L. (2018). Strategi Penguatan Adaptasi dan Mitigasi Bencana Banjir untuk Mengurangi Risiko Usaha Kecil dan Menengah. The 8th University Research Colloquium 2018 Universitas Muhammadiyah Purwokerto, 2012, 239-244.

Ivlev, I., Kneppo, P., \& Bartak, M. (2014). Multicriteria decision analysis: a multifaceted approach to medical equipment management. Technological and Economic Development of Economy, 20(3), $576-589$. https://doi.org/10.3846/20294913.2014.9 43333

Moleong, L. J. (2017). Metode Penelitian Kualitatif. Bandung: PT. Remaja Rosdakarya Offset.

Notosiswoyo, M., dan Suswati, S. (2004). Pemanfaatan Magnetic Resonance Imaging (MRI) Sebagai Sarana Diagnosa Pasien. Media Litbang Kesehatan, 14(3).

Noveranica, D., Hendrartini, Y., dan Hendra, Y. (2017). Evaluasi Kelayakan Investasi Alat MRI Di RSUD Abdul Wahab Sjahranie Samarinda. Universitas Gadjah Mada, Yogyakarta.

Purwana, D. dan Hidayat, N. (2018). Studi Kelayakan Bisnis. Depok: Rajawali Pers. Sugiyono. (2016). Metode Penelitian Kuantitatif, Kualitatif, dan $R \& D$. Bandung: Alfabeta.

Syamsudin; Isa, M; Mangifera, L; Nurhayati, M. . (2019). Studi Kelayakan Penggunaan Bahan Bakar Wood Pellet Pada IKM Nata De Coco Di Kabupaten Sragen. Seminar Nasional \& Call For Paper Seminar Bisnis Magister Manajemen

(SAMBIS-2019) 


\section{Jurnal Ilmiah Manajemen dan Bisnis}

"Membangun Ekonomi Kreatif Yang Berdaya Saing” Magister Manajemen Universitas Muhammadiyah Surakarta. ISSN: 2685-1474, 327-335.

Utomo, S. Joko;Santoso, P.B.; Yuniarti, R. (2006). Perancangan Sistem Pendukung Keputusan Pemilihan Karyawan Terbaik Berbasis 360 Degree Feedback Dan Analytical Hierarchy Process Design of Decision Support System Selection of the Best Employees Based 360 Degree Feedback and Analytical. Rekayasa Dan Manajemen Sistem Industri, 3(1), 110120. 